\title{
Identification of plant agricultural production problems to sugar beet area farmers, Al-Amriya district, Alexandria governorate, Egypt
}

\author{
Houssein A.A.B. \\ Agricultural Extension Programs Research Department, Agricultural Extension \& Rural Development \\ Research Institute, Agricultural Research Center, Ministry of Agriculture and Land Reclamation, Egypt
}

\begin{abstract}
The main aim of this research was to identify some of the social, economic and communication characteristics of the investigated farmers, as well as to identify the most important problems faced by the farmers concerned in the agricultural production in the sugar beet area, with relative importance. The data were collected using a questionnaire from a random sample of 200 respondents from the sugar beet area in Alexandria. The percentage, standard deviation, mean and weighted weights were used to analyze the data and display the results.
\end{abstract}

The results indicated that:

1. The majority of farmers interviewed by $67 \%$ were ignorant, read and write, fluent in reading and writing, has a primary certificate, and holds a preparatory certificate.

2. More than third of the surveyed farmers have a storage capacity of 1-5 acre to $36 \%$.

3. More than $60 \%$ of the farmers interviewed received possession capacity through purchase from others.

4. $95 \%$ of the respondents mentioned that the low level of irrigation water and the diversion of its rotation with increasing salinity of water is one of the most important problems facing the agricultural production of vegetables with a weighted weight 950 , followed by the problem of scarcity of good seeds, fertilizers and pesticides. 


\section{التعرف على مشكلات الإنتاج الزراعي النباتي لزراع منطقة بنجر السكر

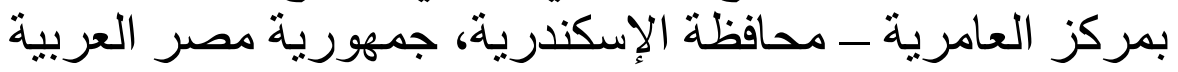

\author{
أحمد عنتر بخيت حسبن
}

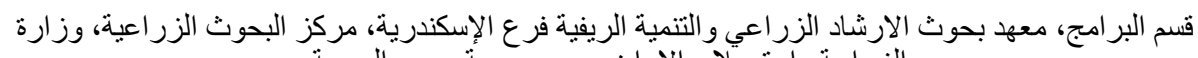 الزراعة وإستصناح الار اضية، جمهورية مصر العربية العربية}

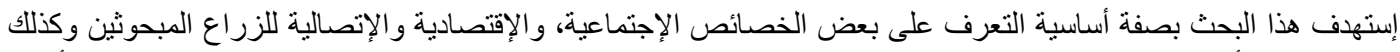

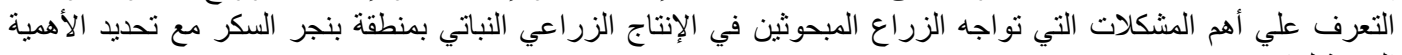
النسبية لها.

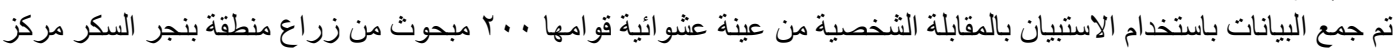

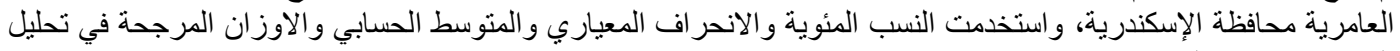
البيانات و عرض النتائج.

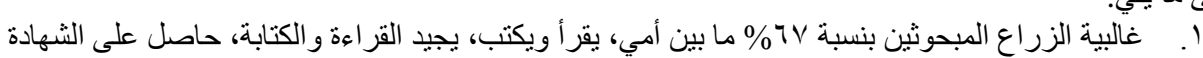
وأثارت النتائج إلى ما يلي: الابتدائية، وحاصل على الزعلى الثهادة الإعدادية.

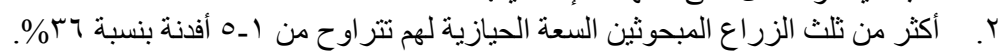

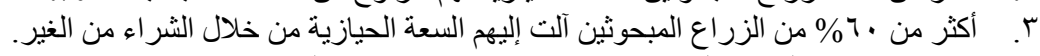

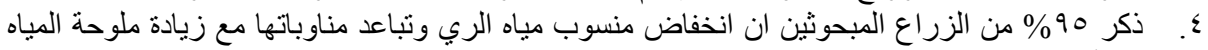

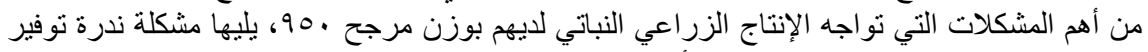

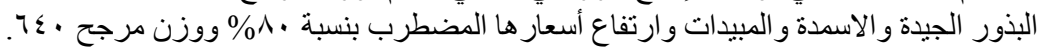

كلمـات دالـة: مشكلات الانتـاج الزراعي النباتي، مشكلات زراع منطقة بنجر السكر، مشكلات الزر اعـة بمحافظة الاسكندرية، مشكلات الأر اضي الجديدة. 
موارد مائية محدودة، ومن هنا استلزم القيام بهذه الدراسة الإناج

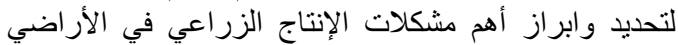

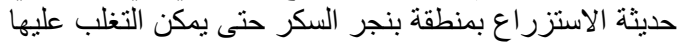

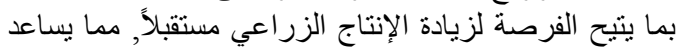

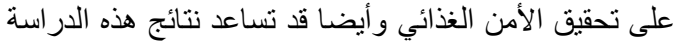

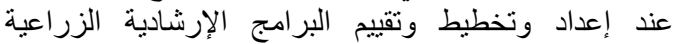
الموجهة للزر اع في الأر اضي الجديدة.

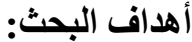

ا. . التعرف على بعض الخصائص الاجتماعية،

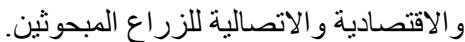

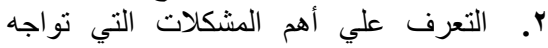

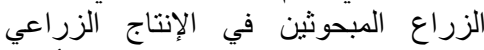

النباتي بمنطقة بنجر السكر مع تحديد الأهمية

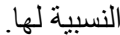

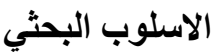

منطقة البحث: منطقة بنجر السكر (مراقبة بنجر السكر)

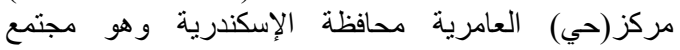

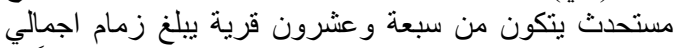

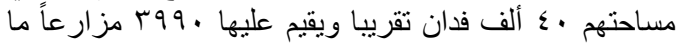

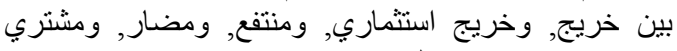

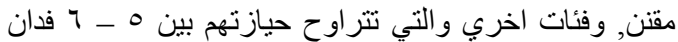

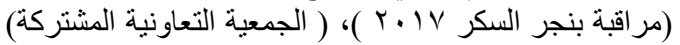

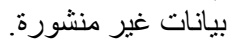

الثاملة والعينة: تمثلت شاملة البحث في جميع زراع منطقة

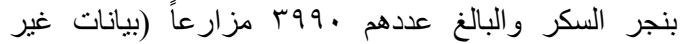

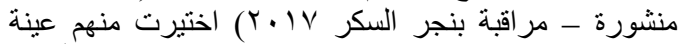

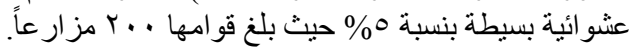

أسلوب جمع البيانات: تم إستيفاء البيانات البحثية بإستخدام

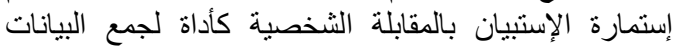

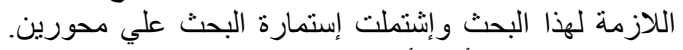

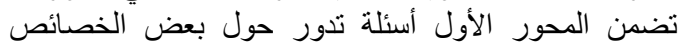

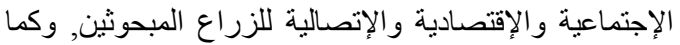

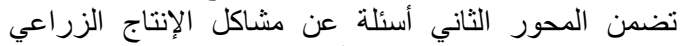

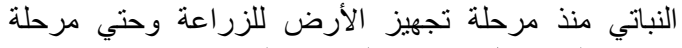

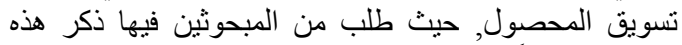

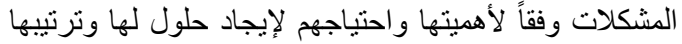
من الأهم للأقل أهمية والتي تعيق العملية الإنتاجية والتتموية

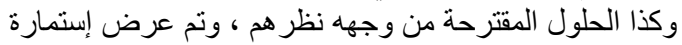

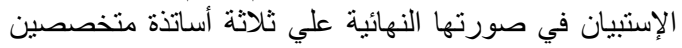

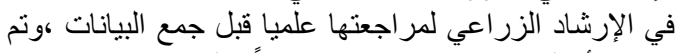
إختبار أسئلة إستمارة الإستبيان مبئياً علي عينة من مربي البنات

\section{المقدمة و المشكلة البحثية}

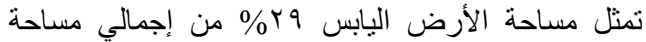

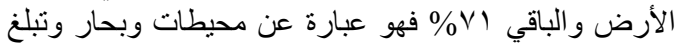

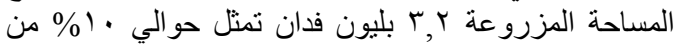

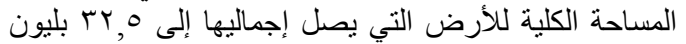

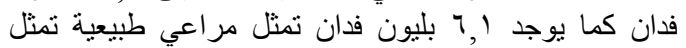

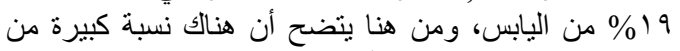

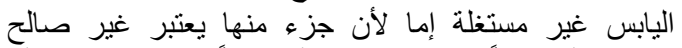

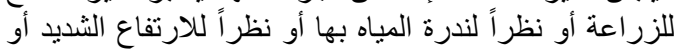

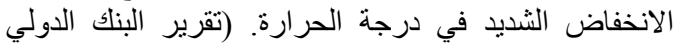

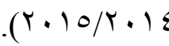

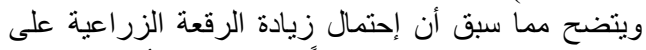

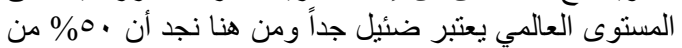

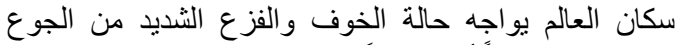
وندرة الغذاء حالياً أو مستقبلاً.

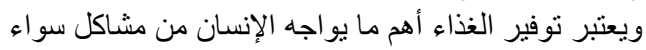

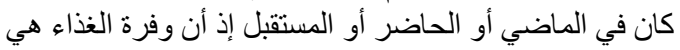

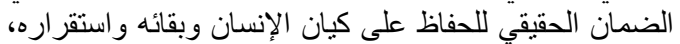

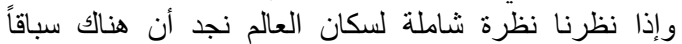

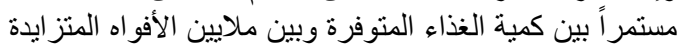

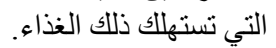
كما يقاس مستوى معيشة الإنسان في أي منطقة في العالم

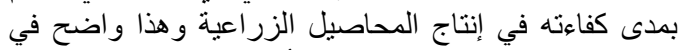

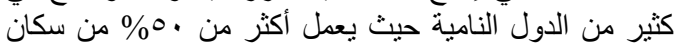

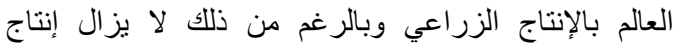

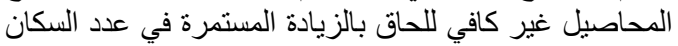

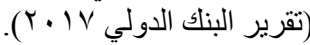
مما أدي لظهور العديد من المشكلات مع الأخذ في الإعتبار

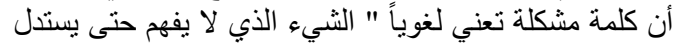

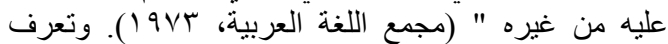

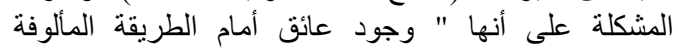

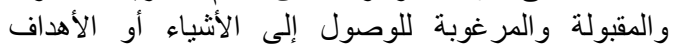

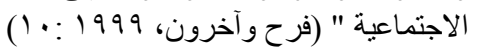

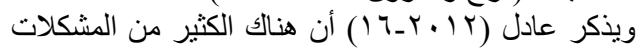

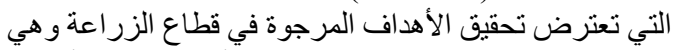

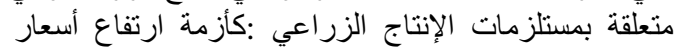

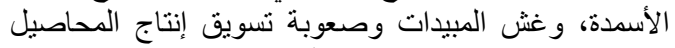

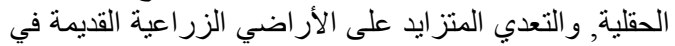

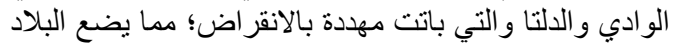

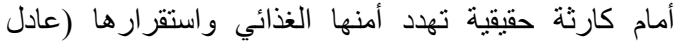

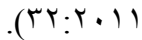

ويواجه تحقيق الأمن الغذائي في جمهورية مصر العربية

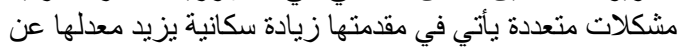

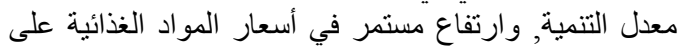
المستوى العالمي و المحلي مع زيادة في في الاستهارلاك في ظل النل 


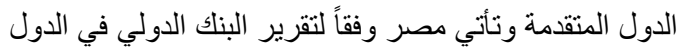

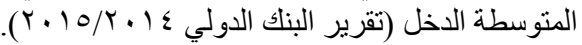
وقد اتفقت هذه الدر اسة مع در اسة كلا من:

1- لمياء سعد الحسيني، علام محمد طنطاوي ـالمشكلات

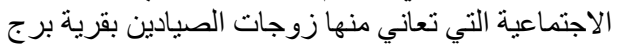

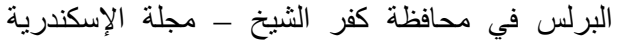

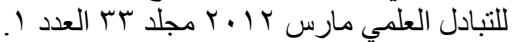

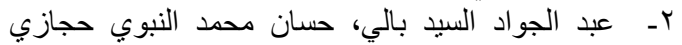

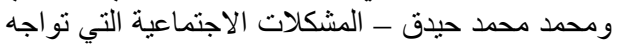

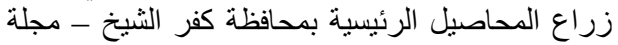

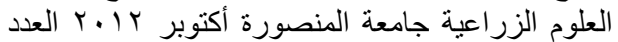

(1.) (1)

قياس المتغيرات البحثية: اشتملت المتغيرات البحثية للاراسة

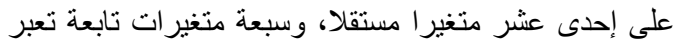

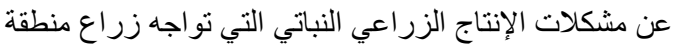
بنجر السكر وتم قياسها كما يلي:

r- السن: تم قياسه بسؤال المبحوث عن السن لأقرب سنة

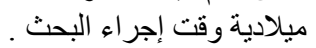

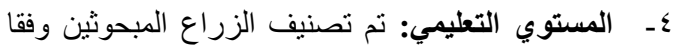

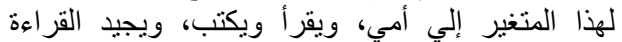

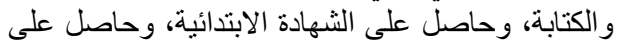
الثهادة الاعدادية، وحاصل على على الثلى الثهادة الثانة الثانوية،

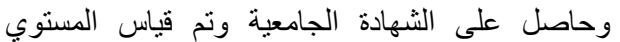
التعليمي بعدد سنو ات التعليم التي اجتاز ها بنجاح.

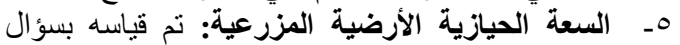
المبحوث عن المساحة الأرضية المزر الرية الرية التي بحوزته لأقرب وحدة أرضية مزر عية وهي الأرية الفدان. T- - مصدر السعة الحيازية الأرضية المزية الفزعية: تم قياسه

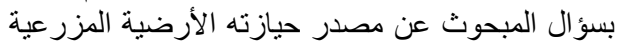

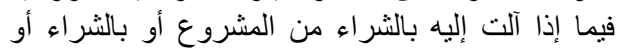
الإيجار من الغير.

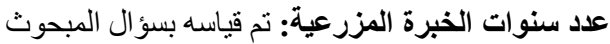

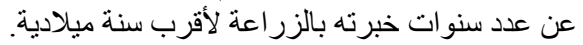

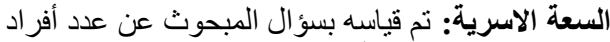

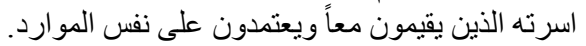

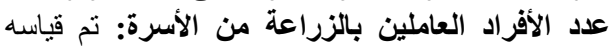
بسؤال المبحوث عن عدد أفراد الأسرة الذين يتخذون الزر اعة عملاً رئيسياً.

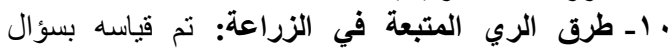

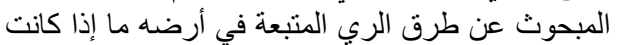

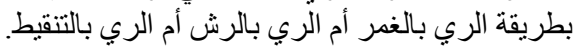

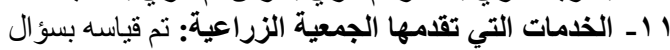

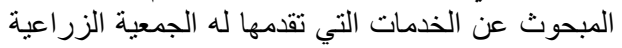

المانثية قوامها م ب مبحوثاً وتم إجراء التعديلات اللازمة

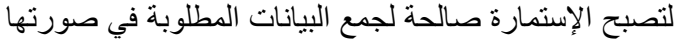
النهائية, وتم جمع بيانات البحث خلارل شهر نوفمبر عام $r+1 \mathrm{~V}$

اسلوب تحليل البيانات: استخدمت الأساليب الإحصائية البسيطة

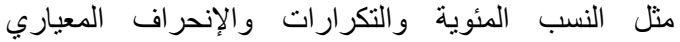

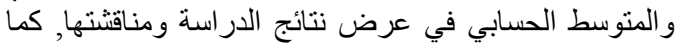
اعتمدت هذه الدراسة علي استخدام مقياس الأوزان المربك المرجحة

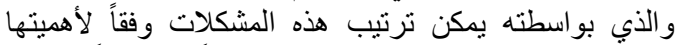

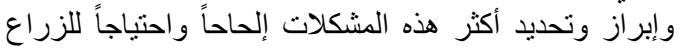

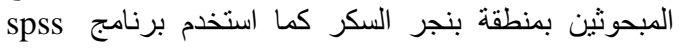

للتحليل الاحصائي (Mc Clave and Sincich, 2006).

الإطار النظري: ندور النظريات الطبيعية حول قانون طبيعي

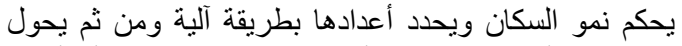

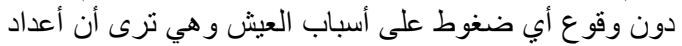

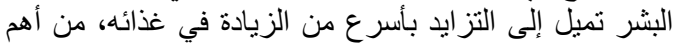

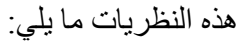

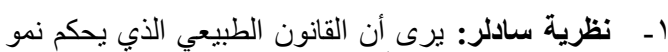

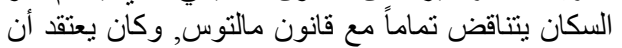

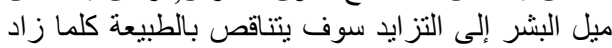
الازدحام السكاني في المر اكز العمر انية النية, وأن أعدادهم

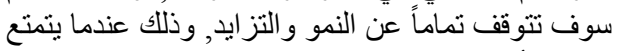
الناس بأكبر قدر من السعادة, وذللك بافتراض اضلت تساوي جميع الأشياء الأخرى.

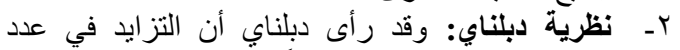

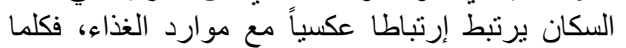

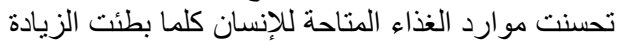

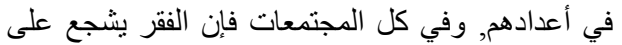

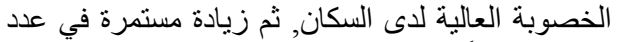

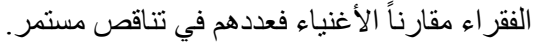

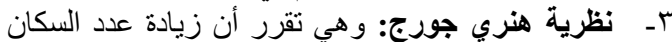

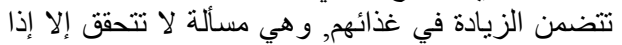

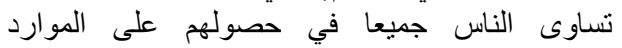

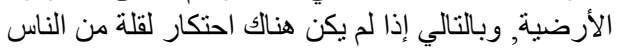

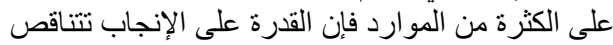

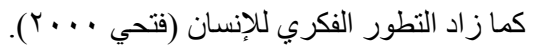

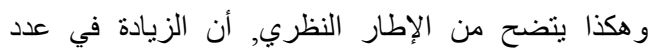

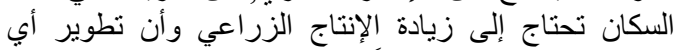

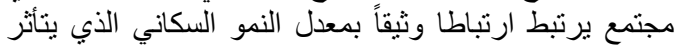
ويؤثر في الدخل الفردي وبالتبعية بالدخل القون القومي.

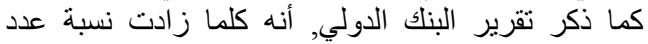

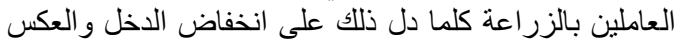

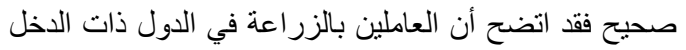

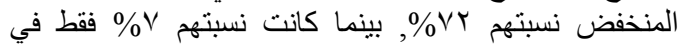


متوسط الحلول المقترحة لهذه المشكلات ؟ب, بانحر اف

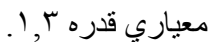
9 1اـ مشكلات الصرف الزراعي: تم قياسه بسؤال المبحوث

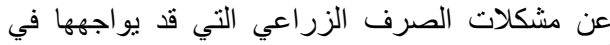

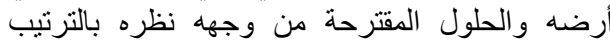

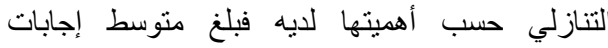

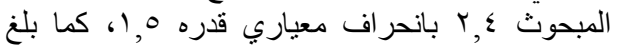

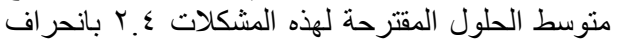

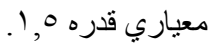
• r- مشكلات التسويق المحصولي الزراعي: تم قياسه بسؤال

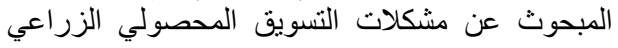

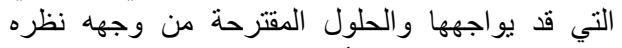

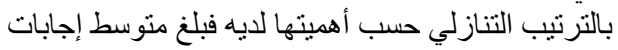

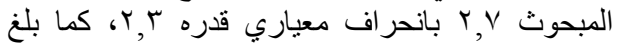

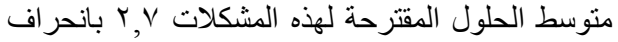

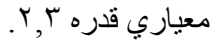

\section{النتائج البحثية ومناقشتها}

أولاً: التعرف على بعض الخصائص الأص الاجتماعية، والاقتصادية والاتصالية للزراع المبحوثين

للتعرف على بعض الخصائص الاجتماعية والاقتصادية والاتصالية للزراع المبحوثين نم توجيه مجموعة من الأنئ الأسئلة

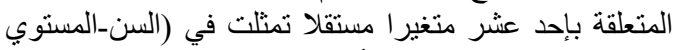

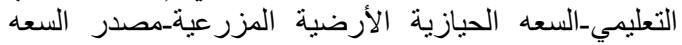

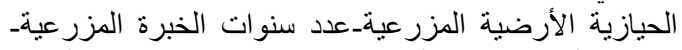

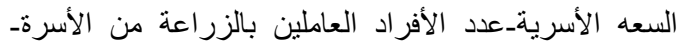

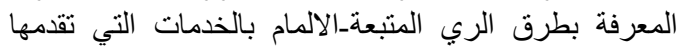

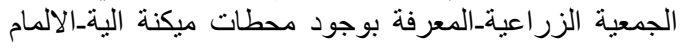
بدور بنك التسليف الزراعي الزئ) كالاتي:

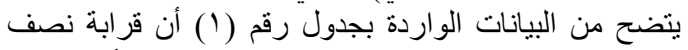

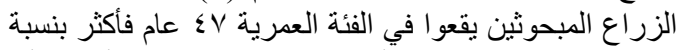

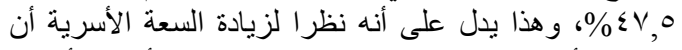

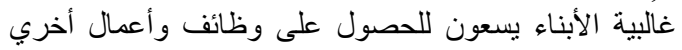

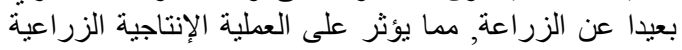

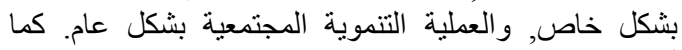

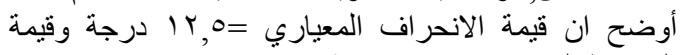

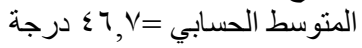

فتم تخيره بين الاستفادة بمستلزمات الإنتاج أم تسويق الإنقاد الزيق

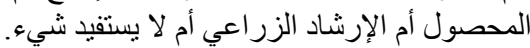

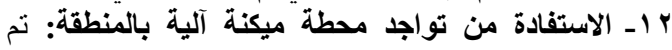

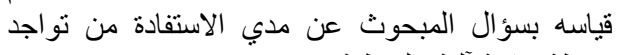

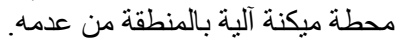

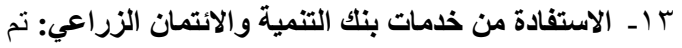

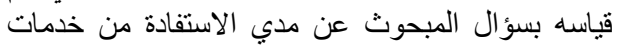

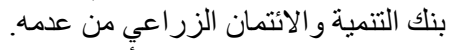

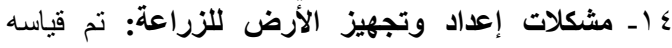

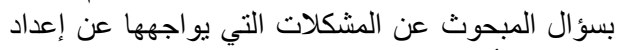

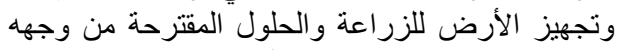

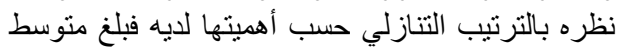

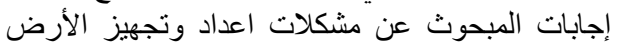

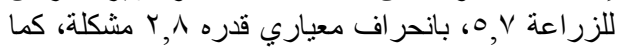

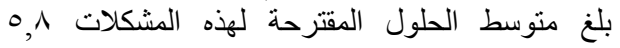

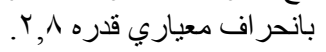

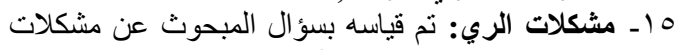

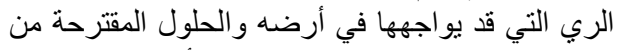

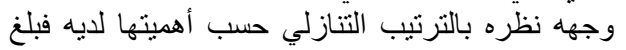

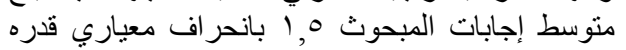

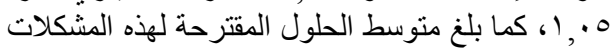

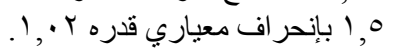

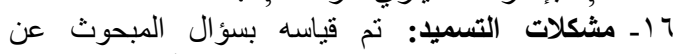

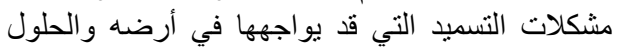

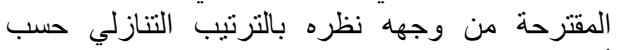

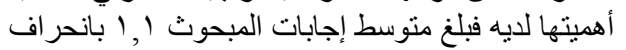

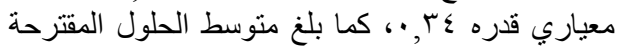

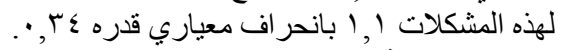

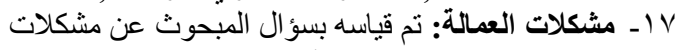

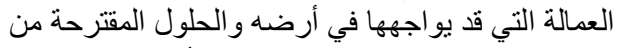

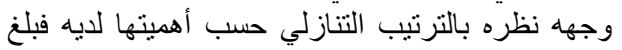

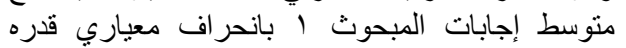

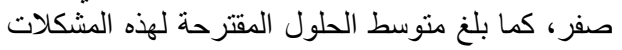

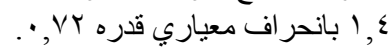

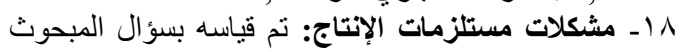

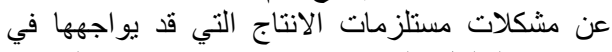

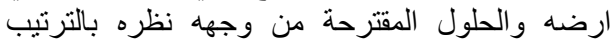

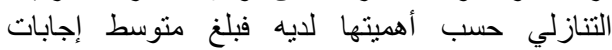

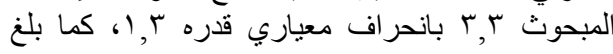

جدول ( ) يوضح نوزيع الزراع المبحوثين وفقا لفئات السن بالسنة

\begin{tabular}{|c|c|c|}
\hline النسبة المئوية & العدد & الفئة \\
\hline rr.o & $\leqslant 0$ & من \& \\
\hline$r$. & 7. & من דr \\
\hline$\varepsilon V_{0} 0$ & 90 & V \ فأكثر \\
\hline $1 \ldots$ & r.. & المجموع \\
\hline
\end{tabular}

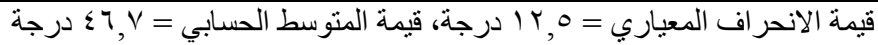




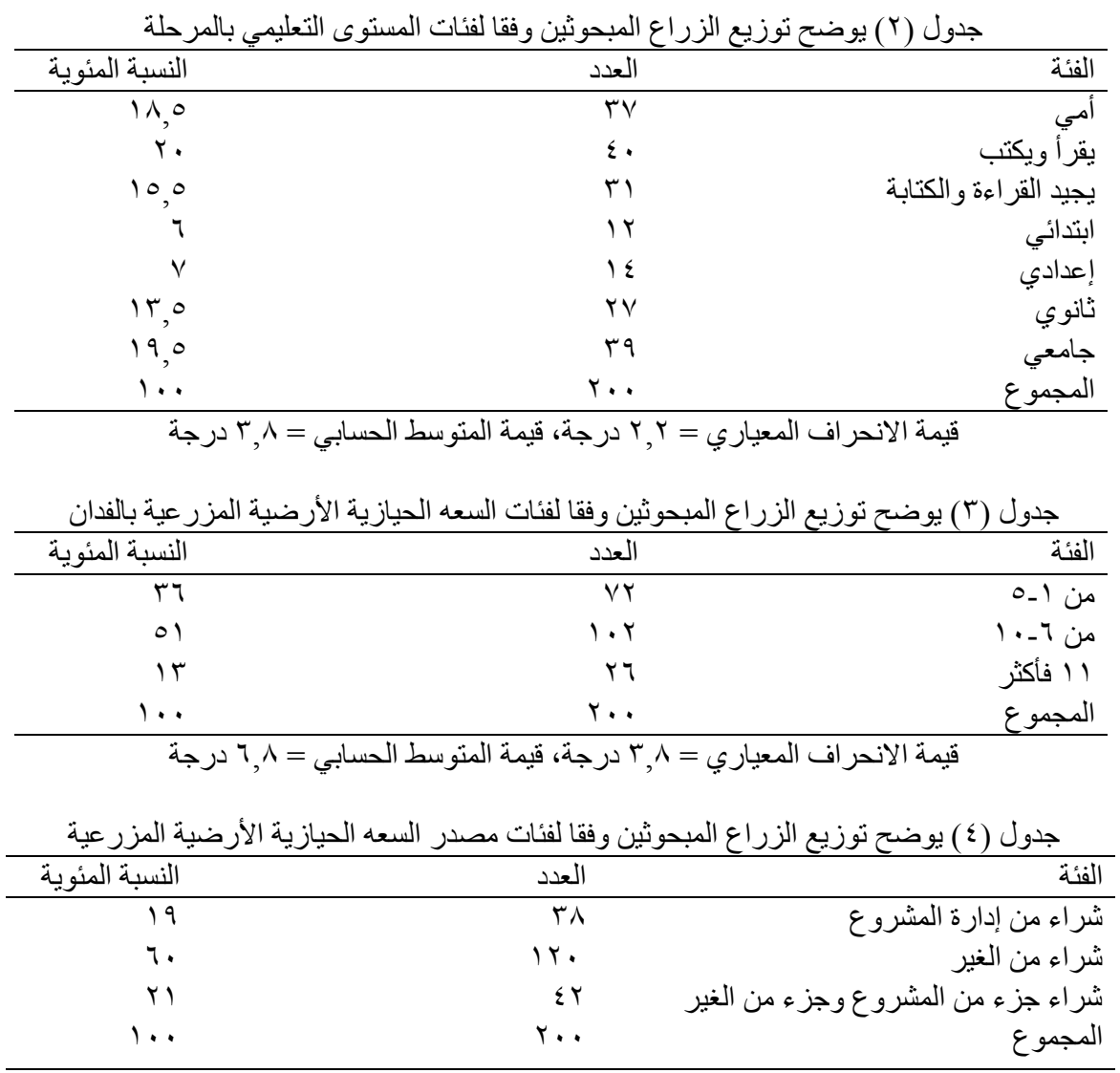

قيمة الانحر اف المعياري = T, · درجة، قيمة المتوسط الحسابي = ب درجة

الحاليين حازوا الأرض عن طريق الثراء من الغير وأن

9 19\% منهم فقط استلم الأرض من المشرو طن و ولا زالت معن.

يتضح من الييانات الواردة بجدول رقم (0) ان غالبية

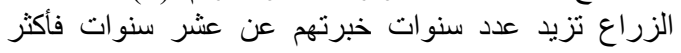

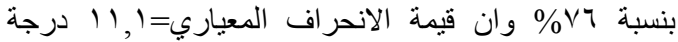

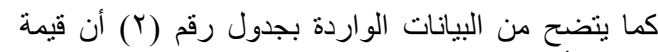

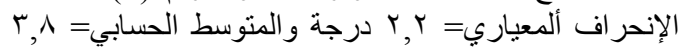

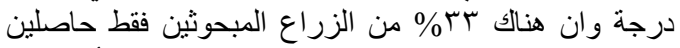

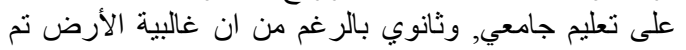

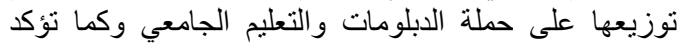

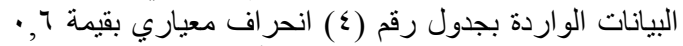

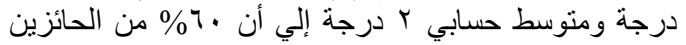

جدول (0) يوضح نوزيع الزراع المبحوثين وفقا لفئات عدد سنوات الخبرة المزرعية بالسنة

\begin{tabular}{|c|c|c|}
\hline النسبة المئوية & العدد & الفئة \\
\hline T纟 & $\varepsilon \wedge$ & من 1- \\
\hline ru, & $V T$ & من|| - - r \\
\hline$r q, 0$ & $\vee q$ & ا Y فأكثر \\
\hline $1 \ldots$ & r... & المجمو ع \\
\hline
\end{tabular}


جدول (†) يوضح نوزيع الزراع المبحوثين وفقا لفئات السعه الأسرية بالفرد

\begin{tabular}{|c|c|c|}
\hline النسبة المئوية & العدد & الفئة \\
\hline$\leq 0$ & 9. & من 1_- \\
\hline$\leqslant \wedge$ & 97 & من 7 - . \\
\hline V & $1 \varepsilon$ & 11 \\
\hline $1 \ldots$ & r.. & المجموع \\
\hline
\end{tabular}

\begin{tabular}{|c|c|c|}
\hline النسبة المئوية & العدد & الفئة \\
\hline 00,0 & 111 & من I-1 \\
\hline rV & $V \varepsilon$ & من T-_ \\
\hline$v, 0$ & 10 & ه فأكثر \\
\hline $1 \ldots$ & r.. & المجموع \\
\hline
\end{tabular}

\begin{tabular}{|c|c|c|}
\hline النسبة المئوية & 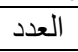 & الفئة \\
\hline$V \leqslant, 0$ & $1 \leq 9$ & غمر \\
\hline$\wedge$ & 17 & تنقيط \\
\hline iv, 0 & ro & جزء بالغمر وجزء بالتتقيط \\
\hline $1 \ldots$ & r.. & المجموع \\
\hline
\end{tabular}

قيمة الانحر اف المعياري = Y, ب درجة، قيمة المتوسط الحسابي = V, ا درجة

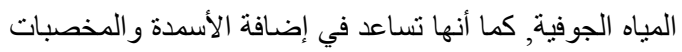

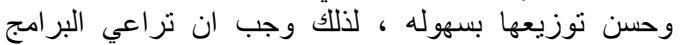

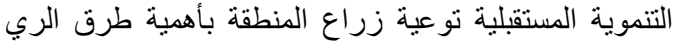

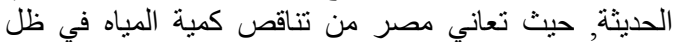

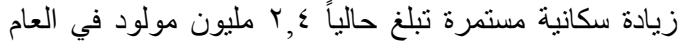

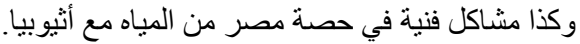

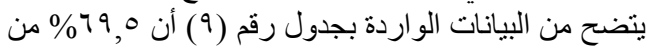

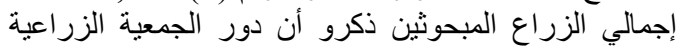

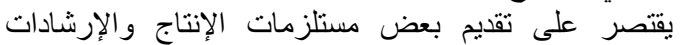

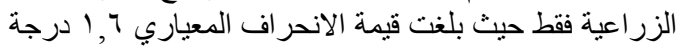

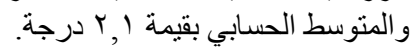

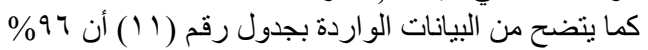

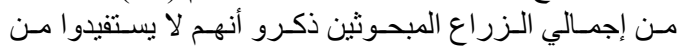

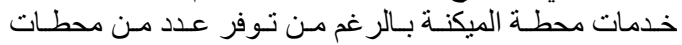

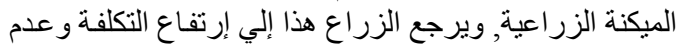

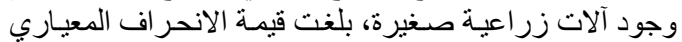

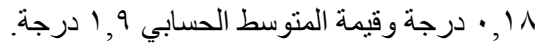

يتضح من البيانات الواردة بجدول رقم (V) أن أن غالبية

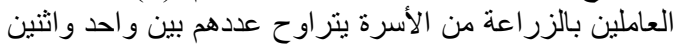

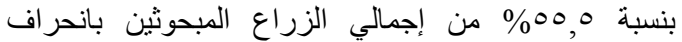

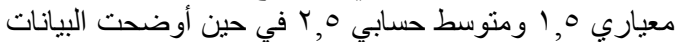

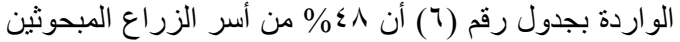

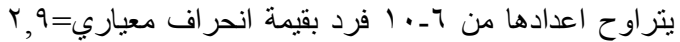

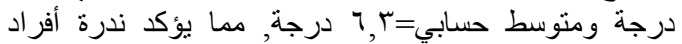

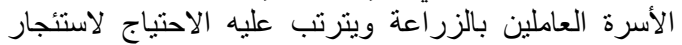

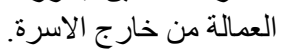

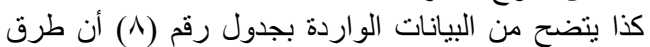

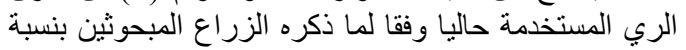

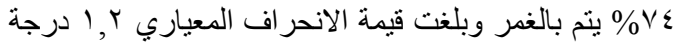

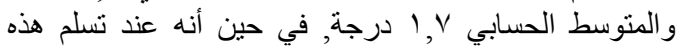

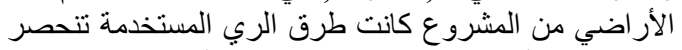

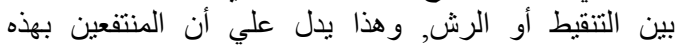

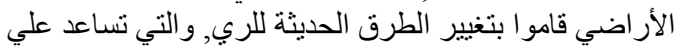

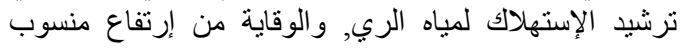




\begin{tabular}{|c|c|c|}
\hline النسبة المئوية & 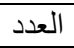 & الفئة \\
\hline $0 \wedge .0$ & 118 & مستلزمات الإنتاج \\
\hline 10 & r. & تسويق المحصول \\
\hline 11 & rt & إرشاد زر اعي \\
\hline 10.0 & $M$ & لا أستفيد أي خدمات من الجمعية \\
\hline $1 \ldots$ & $r \cdot$ & المجموع \\
\hline
\end{tabular}

\begin{tabular}{|c|c|c|}
\hline النسبة المئوية & العدد & الفئة \\
\hline$V 0,0$ & 101 & نعم توجد \\
\hline$r \leqslant, 0$ & $\leqslant 9$ & لا توجد \\
\hline $1 \ldots$ & $r .$. & المجموع \\
\hline
\end{tabular}

جدول (1) يوضح توزيع الزراع المبحوثين وفقا لفئات الاستفادة من تو اجد محطة ميكنة آلية بالمنطقة

\begin{tabular}{|c|c|c|}
\hline النسبة المئوية & العدد & الفئة \\
\hline r.o & V & أستفيد \\
\hline 97,0 & 194 & لا أستفيد \\
\hline $1 \cdots$ & r.. & المجموع \\
\hline
\end{tabular}

الزراع المبحوثين هذا إلي عدم معرفتهم الكاملة بالخدمات التي

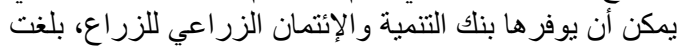

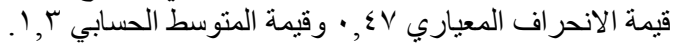

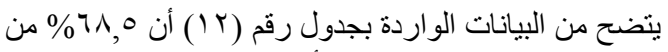

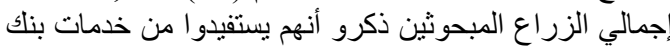

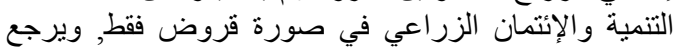
جدول (r ( ) يوضح توزيع الزراع المبحوثين وفقا لفئات الاستفادة من بنك التنمية والائتمان الزر اعي

\begin{tabular}{|c|c|c|}
\hline النسبة المئوية & العدد & الفئة \\
\hline $7 \wedge, 0$ & ITV & أستفيد \\
\hline T, 0 & אדי & لا أستفيد \\
\hline $1 \ldots$ & r.. & المجمو ع \\
\hline
\end{tabular}

\section{ثانياً: التعرف علي أهم المثكلات التي تواجه الزراع المبحوثين في الإنتاج الزراعي التباتي بمنطقة بنجر السكر}

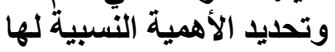

جدول (س ا ) يوضح ثوزيع الزر اع المبحوثين وفقا لأهم مشكلات الإنتاج الزر اعي النباتي من وجهة نظر هم بمنطقة بنجر السكر

\begin{tabular}{|c|c|c|}
\hline النسبة المئوية & 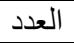 & 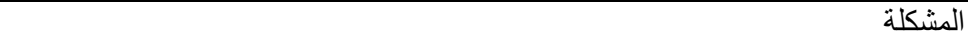 \\
\hline 90 & 19. & أنخفاض منسوب مياه الري وتباعد مناوباتها مع زيادة ملوحة المياه. \\
\hline A. & 17. & ندرة توفير البذور الجيدة والأسمدة والمبيدات وارتفاع أسعار ها المضطرب. \\
\hline 70 & $1 \mathrm{H}$ & إنتشار بعض الآفات الحشرية في ظل انخفاض خصوبة التربة. \\
\hline ०. & $1 \cdots$ & عدم توفر الآلات الزراعية الحديثة مع ندرة العمالة الزر اعية \\
\hline ro & $\checkmark \cdot$ & و مستلز مات السعار الوقتاجد وتأثثيره على العمليات الزر اعية المختلفة ونقل الحاصلات الزر اعية \\
\hline
\end{tabular}


ملحوظة: تم توجيه السؤ ال للزراع المبحوثين بأن يذكر أهم المشكلات التي نواجهه بالترتيب التنازلي حسب أهميتها لديه.

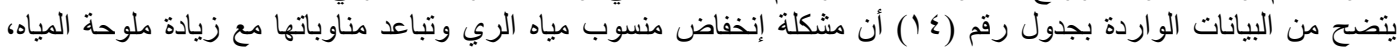

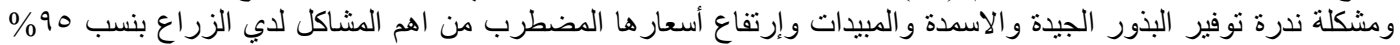

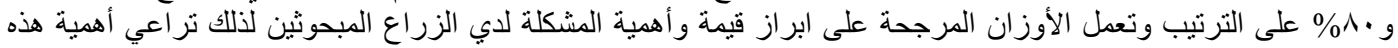

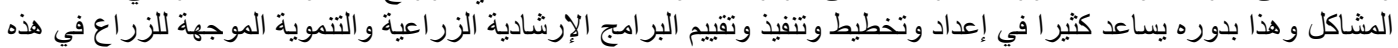

المنطقة.

جدول (ـ ا) يوضح نوزيع الزراع المبحوثين وفقا للأوزان المرجحة لأهم مشكلات الإنتاج الزراعي النباتي من وجهة نظرهم

\begin{tabular}{|c|c|c|c|c|}
\hline 90. & 0 & 90 & 19. & إنخفاض منسوب مياه الري وتباعد مناو باتها مع زيادة ملوحة المياه. \\
\hline$\uparrow \leq$. & $\varepsilon$ & $\wedge$. & 17. & ندرة توفير البذور الجيدة والأسمدة والمبيدات وارتفاع أسعار ها المضطرب. \\
\hline rq. & r & 70 & $1 \mathrm{~s}$ & انتشار بعض الآفات الحشرية في ظل انخفاض خصوبة التربة. \\
\hline r.. & r & ○. & $1 \cdots$ & عدم توفر الآلات الزر اعية الحديثة مع ندرة العمالة الزر اعية. \\
\hline$v \cdot$ & 1 & ro & $v$. & الزراعية ومستلزمات الإنتاج. الوقاتُثيره على الَعمليات الزراعبة المختلفة ونقل الحاصلات \\
\hline
\end{tabular}

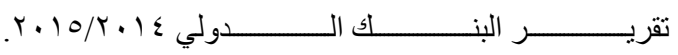

https://angelcraftcrownworldbankreserve.f iles.wordpress.com/2015/04/acwbr_ar_ne w-world-bank-annual-report-2014_ard8aad982d8b1d98ad8b1d8acd8afd98ad8afd984d984d8a8d986d983d8a7d984d8afd988d984d98a.d8b9d8a7d985-2014-d8a7.pdf

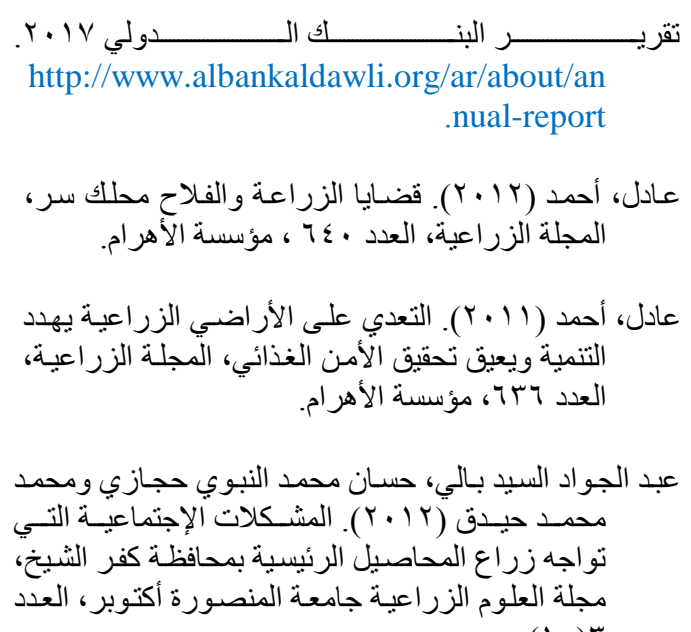
.nual-report

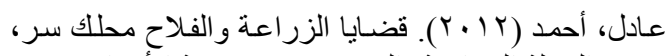

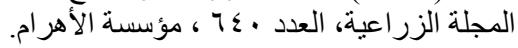

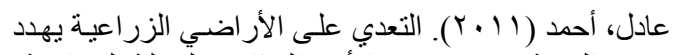

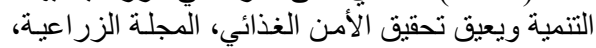

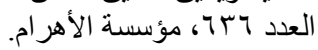

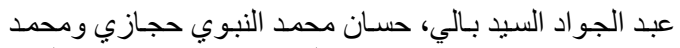

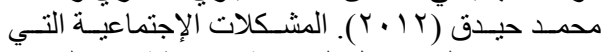

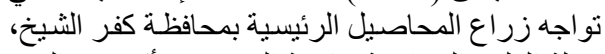

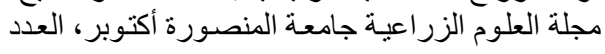
$(1 \cdot)^{r}$
التوصيات

في ضوء النتائج السابقة يمكن التوصية بما يلي:

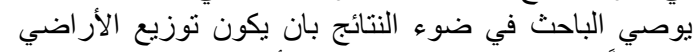

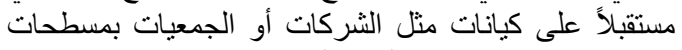

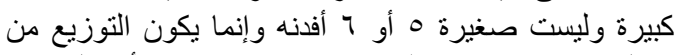

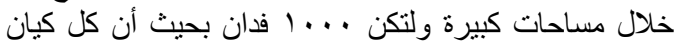

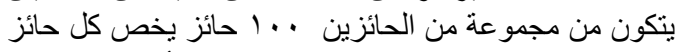

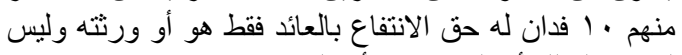

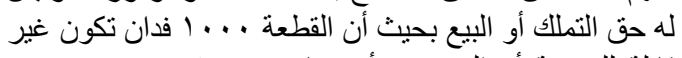

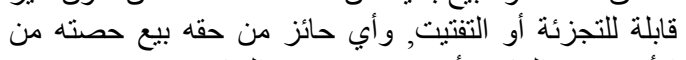

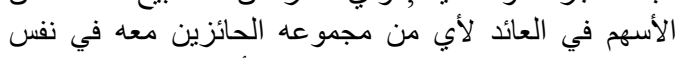

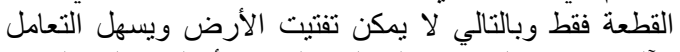

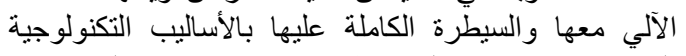
الحديثة مما يساعد علي تعظيم الإنتاج وتضييق الإلئي الفجوة بين

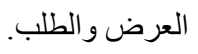

\section{قائمة المراجع مراجع باللغة العربية}

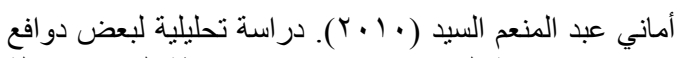

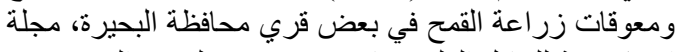

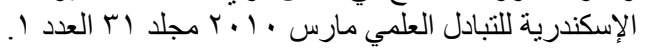




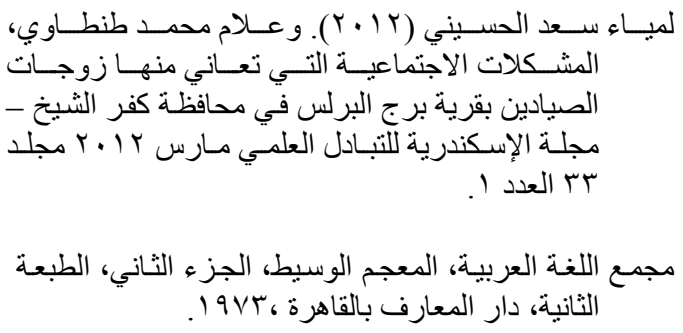

\section{مراجع باللغة الإنجليزية}

Abdulhalim and Md. Mozahar Al (1997), "Training and Professional Development", in Burton E. Swanson, Robert P. Bentz, and Andrew J. Sofranko (Ed.), Improving Agricultural Extension,

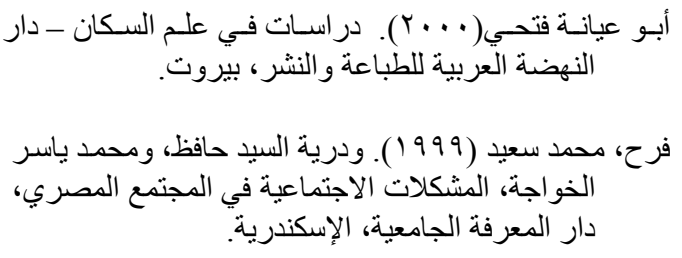

FAO, Rome. 